\title{
VIS-NIR Reflectance Spectroscopy for Assessment of Soil Microbiological Properties
}

\author{
Bhabani Prasad Mondal $^{1 *}$, Bharpoor S. Sekhon ${ }^{1}$, Sandeep Sharma ${ }^{1}$, \\ Manjeet Singh $^{2}$, Rabi N. Sahoo ${ }^{3}$, Arijit Barman', Yagani Sinha ${ }^{4}$, \\ Arghya Chattopadhyay ${ }^{6}$ and Koushik Banerjee ${ }^{3}$
}

\author{
${ }^{1}$ Department of Soil Science, ${ }^{2}$ Department of Farm Machinery and Power Engineering, \\ Punjab Agricultural University, Ludhiana, Punjab-141004, India \\ ${ }^{3}$ Division of Agricultural Physics, Indian Agricultural Research Institute, \\ New Delhi-110012, India \\ ${ }^{4}$ Division of Soil and Crop Management, ICAR-Central Soil Salinity Research Institute, \\ Karnal, Hariyana-132001, India \\ ${ }^{5}$ Department of Soil Science and Agricultural Chemistry, Dr. Panjabrao Deshmukh Krishi \\ Vidyapeeth, Akola, Maharastra-444104, India \\ ${ }^{6}$ Department of Soil Science and Agricultural Chemistry, \\ Banaras Hindu University, Varanasi-221005, India \\ *Corresponding author
}

\section{A B S T R A C T}

\section{Keywords}

Dehydrogenase, Land use, Microbial biomass carbon, Reflectance spectroscopy, VIS-NIR models.

Article Info

Accepted:

07 October 2017

Available Online:

10 December 2017
Soil microbes play an important role in major processes of soil system. Rapid, reliable and cost effective assessment of soil microbiological properties is highly essential for monitoring soil health. Traditional chemical-based soil analysis is laborious, hazardous and time consuming. Visible near-infrared (VIS-NIR) reflectance spectroscopy can be a viable alternative to ensure rapid and environmentally safe soil test results. With this objective, two key soil microbiological parameters microbial biomass carbon (MBC) and dehydrogenase activity (DHA) were examined for their amenability to diffuse reflectance spectroscopy assessment. Geo referenced surface soil $(0-15 \mathrm{~cm})$ samples $(\mathrm{n}=170)$ were collected from different fields for spectral analysis. Partial least square regression (PLSR) technique was employed for developing spectral models. The different model evaluation indices like coefficient of determination $\left(\mathrm{R}^{2}\right)$, root mean square error of prediction (RMSE) and ratio of performance deviation (RPD) were used to evaluate the predictive performance of model. The RPD values for MBC and DHA were 1.15 and 1.13. Poor predictive performance of our model as opposed to substantial evidence in literature can be ascribed to range of factors like limited variability in spectra, relatively smaller sample size, use of entire spectra instead of selective regions and use of samples collected under natural farm environment as opposed to those generated under controlled conditions. 


\section{Introduction}

Soil microbes play significant role in maintaining soil health and fertility status. Soil properties especially soil microbiological properties vary both spatially and temporally. Microbial biomass carbon (MBC) though contributes insignificantly to total organic carbon pool of the soil but it plays a key role in litter decomposition, nutrient cycling and energy transfer in soil (Xu et al., 2014). Soil $\mathrm{MBC}$ has been shown to exhibit considerable spatial variation (Xu et al., 2013). Likewise, soil enzymes play a vital role in organic matter decomposition and nutrient cycling and their activities are linked closely with soil physic-chemical properties (Amador et al., 1997), microbial community make-up (Kourtev et al., 2002), vegetation (Boerner et al., 2000) etc. Consequently, variation in these properties gets translated into variation in microbiological properties. Dehydrogenase (DHA) enzyme has been reported to vary substantially with change in soil properties including slope, micro sites and soil depth (Cao et al., 2011). Such variation of soil microbiological properties should be assessed rapidly in a cost effective way for management of soil production capacity as well as health. Conventional chemical-based techniques are not however rapid and capacious enough to allow timely and comprehensive assessment in order to override the spatial variability of such properties. Visible-near infrared (VIS-NIR) reflectance spectroscopy holds a huge promise in this regard as it provides rapid, reliable, non-destructive and cost effective assessment of soil microbiological properties. VIS-NIR spectral region $(350-2500 \mathrm{~nm})$ is highly useful for routine evaluation purpose of various soil properties including microbiological properties. VIS-NIR spectra specially near-infrared spectra are influenced by physical properties like shape, size of soil separates and void spaces in between them, arrangement of major particles and also by chemical nature and by the presence of different fundamental vibrational bands like H-C, H-O, H-N etc. (Wetzel, 1983). Besides, a single spectrum can be used for simultaneous assessment of various soil properties. Multivariate statistical modeling techniques like partial least square regression (PLSR), multivariate adaptive regression spines (MARS), principal components regression (PCR) etc. are used to correlate the spectra with the measured properties. There exist many studies that report differently on the potential of VIS-NIR spectroscopy technique in assessing soil microbiological properties. No matter, the spectral library approach (Shepherd and Walsh, 2002) can be successfully used for generalizing soil test data, conducted in limited number of sites, and then extended to other sites also thereby increasing the efficiency of expensive and time consuming traditional soil analysis, but given the site specific dependence of microbiological properties, the potential of spectroscopic technique needs to be assessed at such a landscape scale that it involves a range of land use types. Thus, the study in hand was conducted to evaluate the potential of VIS-NIR reflectance in assessing two key microbiological parameters-MBC and DHA at a landscape scale, that involves three land use types in an agriculturally intensive region of northwest India.

\section{Materials and Methods}

\section{Description of study area}

The soil samples were collected from three different farmers' field following three different land use systems viz., berseem (Egyptian clover, Trifolium alexandrinum L) based land use $(\mathrm{Br})$, rice-wheat system (RW) and poplar-wheat system (PW). The berseem based land use type was situated $\left(30^{\circ} \quad 57^{\prime}\right.$ 329 " $\mathrm{N}$ and $75^{\circ} 47^{\prime} 609^{\prime \prime} \mathrm{E}$ ) in Ladian village (226 meters above mean sea level) of Ludhiana district of Punjab state of India (Fig. 
1). The second land use type $\left(30^{\circ} 57,330^{\prime \prime} \mathrm{N}\right.$ and $75^{\circ} 47^{\prime} 675^{\prime \prime}$ E) located in the environs of the first system and had been under continuous rice-wheat sequence for the past 10 years. The third site with sandy clay texture located $\left(30^{\circ} 57^{\prime} 659^{\prime \prime} \mathrm{N}\right.$ and $75^{\circ} 47^{\prime}$ 665 " E) in the vicinity supported a five year old poplar plantation that had been intercropped with wheat for three years. Relatively high organic carbon content and finer texture (clayey texture) suggested considerable microflora count.

\section{Soil Sample collection and preparation}

Geo referenced (using Trimble SB Handheld Global Positioning System) surface $(0-15 \mathrm{~cm})$ soil samples $(n=170)$ were collected from these three different land use systems. A part of freshly collected samples was kept in refrigerator at prescribed temperature for analysis of microbial biomass carbon (MBC) and dehydrogenase activity (DHA).

The other part of the sample was air dried under shade, crushed with a wooden $\log$ to break the clods and aggregates and visible root fragments were removed; afterwards each sample was sieved through a $2 \mathrm{~mm}$ sieve and then split into two sub-samples. One subsample was used for laboratory analysis of some important physico chemical properties and another subsample was kept for measurement of spectral reflectance.

\section{Laboratory analysis}

\section{Chemical and biological properties analysis}

The properties like $\mathrm{pH}$, electrical conductivity (EC) and soil organic carbon (SOC) were analyzed by following standard analytical procedures like potentiometric method for $\mathrm{pH}(J a c k s o n$ 1973), Conduct metric analysis for EC in 1:2 soil: water suspension (Janzen, 1993) and Walkley and Black method (1934) for determination of SOC.
Soil microbial biomass carbon (MBC) was estimated by following direct extraction method given by Gregorich et al., (1998) by using $0.5 \mathrm{M} \mathrm{K}_{2} \mathrm{SO}_{4}$ as an extractant and chloroform as a fumigant. Chloroform labile carbon was calculated as the difference between the carbon extracted from the chloroform fumigated and the non-fumigated subsamples. No conversion factor was used for conversion of chloroform labile carbon to microbial biomass carbon because the values of conversion factor varied widely (0.41 to 0.58 ) and there was no standard value of this conversion factor.

The dehydrogenase activity (DHA) was determined by the method given by Tabatabai (1982), in which Triphenyl tetrazolium chloride (TTC) got reduced to form a red colored compound triphenyl formazon (TPF). The activity was quantified by measuring the absorbance at $485 \mathrm{~nm}$ on the UV-Visible spectrophotometer.

\section{Reflectance spectra measurement of soil samples}

Spectral reflectance of air dried surface soil samples was recorded by using ASD Fields pec Pro spectroradiometer (Analytical Spectral Devices Inc., Boulder, Colorado, USA) in the spectral range of 350 to $2500 \mathrm{~nm}$ and with $1 \mathrm{~nm}$ sampling interval. Each soil sample was poured in black colored petridish with the help of a contact probe (Contact Probe, Analytical Spectral Devices, Boulder, $\mathrm{CO}$ )having own light source with direct contact on soil surface of petridish in a dark chamber so as rule out extraneous noise. The upper portion of the soil sample in petridish was scrapped to create a smooth surface for easy reading and to minimize noise. Before taking the reflectance spectra of sample, the instrument was calibrated by taking 30 white reflectance spectra in calibrated white Spectralon ${ }^{\circledR}$. Then again instrument noise was minimized by averaging 30 spectra for 
each sample. The plot between relative reflectance values and different wavelengths help to detect the variation in overall spectral shape of the various samples.

\section{Spectral data processing and transformation}

To begin with, huge dimensional space of reflectance values i.e. 2151 data points obtained from spectral measurement in spectral range of 350-2500 $\mathrm{nm}$ was reduced by resampling at $10 \mathrm{~nm}$ interval.

After that, the $10 \mathrm{~nm}$ raw spectra were transformed to their first order derivatives by applying Savitzky-Golay (Savitzky and Golay 1964) transformation in Unscrambler 10 software (CAMO software, Norway).

The equation used for $1^{\text {st }}$ derivative transformation as follows:

$\mathrm{D}_{\mathrm{i}}=\mathrm{d} \alpha / \mathrm{d} \lambda=\left[\alpha_{(\lambda+\Delta \lambda)}-\alpha_{(\lambda-\Delta \lambda)}\right] / 2 \Delta \lambda$ Equation (1).

Where, $\lambda=$ wavelength and $\alpha=$ reflectance.

\section{Statistical modeling indices}

The whole sample set $(n=170)$ was divided into two parts i.e. 113 sample for calibration and 57 samples for validation to develop the spectral model. Partial least square regression (PLSR) modeling technique was used to calibrate the newly developed spectral model in Unscrambler 10 software. In calibration dataset, square root transformation was used for $\mathrm{MBC}$ and DHA for normalization. Coefficient of determination $\left(\mathrm{R}^{2}\right)$ in validation dataset, root mean square error of prediction (RMSEP) and ratio of performance deviation (RPD) indices were used to select the best spectral model. These indices are elaborated mathematically as under:

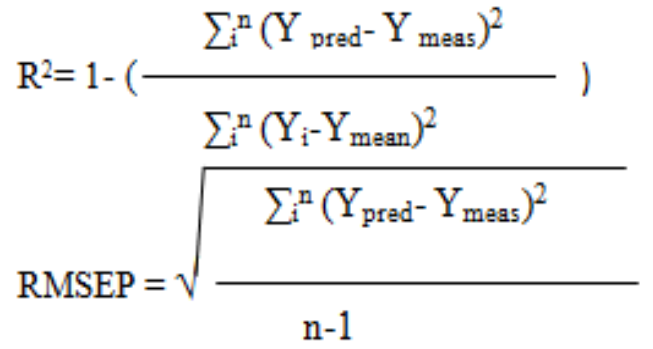

$\mathrm{RPD}=\mathrm{SD}$ val $/$ RMSEP

Equation (2), (3) and (4).

Where, $\mathrm{Y}_{\text {pred }}=$ predicted values; $\mathrm{Y}_{\text {mean }}=$ mean of measured values; $\mathrm{Y}_{\text {meas }}=$ measured values; $\mathrm{n}=$ number of predicted or measured values with $\mathrm{I}=1,2, \ldots \mathrm{n} ; \mathrm{SD}_{\mathrm{val}}=$ standard deviation of measured values in the validation dataset; and RMSEP $=$ root mean square error of prediction in validation dataset.

\section{Results and Discussion}

\section{Chemical and microbiological properties analysis}

The chemical analysis revealed that the mean $\mathrm{pH}$ values of these three different land use systems (Br, RW and PW) were 7.84, 7.88 and 8.17 respectively; mean $\mathrm{EC}$ values were $0.53,0.47$ and $0.41 \mathrm{dS} \mathrm{m}^{-1}$ respectively and mean SOC contents were $0.89,0.87$ and 0.67 $\%$ respectively. The neutral to moderately alkaline $\mathrm{pH}$ values and normal EC values $\left(<0.8 \quad \mathrm{dS} \quad \mathrm{m}^{-1}\right) \quad$ suggested favorable environment for microbial growth. The SOC contents were equally adequate for normal microbial growth.

The MBC followed the order: berseem>ricewheat>poplar-wheat. The MBC in berseem land use ranged from 120 to $390 \mu \mathrm{g} \mathrm{g}^{-1}$ around a mean value of $181.3 \mu \mathrm{g} \mathrm{g} \mathrm{g}^{-1}$ with a coefficient of variation (CV) of $40.8 \%$. In rice-wheat system, it stayed around a mean value of $114.37 \mu \mathrm{g} \mathrm{g}^{-1}$ and showed a range of 60.00 to $270 \mu \mathrm{g} \mathrm{g}^{-1}$ with a CV value of $36.1 \%$. 
In poplar-wheat based agro-forestry system, the microbial biomass carbon revolved within the range of 30 to $210 \mu \mathrm{g} \mathrm{g}^{-1}$ around a mean value of $94.36 \mu \mathrm{g} \mathrm{g}^{-1}$ with $46 \% \mathrm{CV}$. In berseem land use, DHA varied from 1.36 to $4.60 \mu \mathrm{g} \mathrm{TPF}^{-1} \mathrm{hr}^{-1}$ with a mean value of 2.63 $\mu \mathrm{g} \mathrm{TPF}{ }^{-1} \mathrm{hr}^{-1}$ and a coefficient of variation of $28.5 \%$.In rice-wheat cropping system, the activity revolved within the range of 0.64 to $4.80 \mu \mathrm{g} \mathrm{TPF}^{-1} \mathrm{hr}^{-1}$ around a mean value of $2.74 \mu \mathrm{g} \mathrm{TPF}^{-1} \mathrm{hr}^{-1}$ with $36.1 \%$ coefficient of variation. Poplar-wheat system exhibited highest variability in dehydrogenase activity $(51.6 \% \mathrm{CV})$ and it stayed around a mean value of $1.78 \mu \mathrm{g} \mathrm{TPF}^{-1} \mathrm{hr}^{-1}$ and with a range of 0.41 to $4.21 \mu \mathrm{g} \mathrm{TPF}{ }^{-1} \mathrm{hr}^{-1}$.

The SOC content and clay content were significantly higher in all land use system. Higher SOC and clay content significantly increase $\mathrm{MBC}$ and DHA activity. Berseem based land use has significantly higher MBC content due to higher clay and mean SOC content. DHA is significantly higher in ricewheat based cropping system. So the microbiological parameters are significantly correlated with clay and SOC content. These parameters also showed greater variation and indicated the study of spatial variation through modern techniques.

\section{Spectral reflectance characteristics of samples}

Due to variety in chemical and mineralogical, physical and geometrical composition and moisture content, soil samples showed different spectral reflectance characteristics.
The reflectance spectra exhibited characteristics absorption features at 1400, 1900 and $2200 \mathrm{~nm}$ due to presence of water absorption bands at 1400 and $1900 \mathrm{~nm}$ and hydroxyl absorption (-OH) band at $2200 \mathrm{~nm}$ i.e. the decrease in spectral reflectance values around these wavelengths.

All the examined soil samples were relatively abundant in organic carbon and so the spectral reflectance decreased with increase in organic carbon content as reported by Bowers and Hanks (1965).The complex nature and presence of many functional groups in soil organic matter (carbon), makes it spectrally active in NIR region. The absorption around $1400 \mathrm{~nm}$ (specifically $1460 \mathrm{~nm}$ ) indicates the presence of (-OH-) group in water or cellulose and $\left(-\mathrm{CH}_{2}-\right)$ group in lignin.

The $10 \mathrm{~nm}$ raw spectra and the reflectance spectra of first derivative of soil samples are shown in Figure 2 and 3. First derivative transformation helped to find out the major diagnostic features (as indicated by various positive and negative peaks) in spectra related to soil microbiological properties.

Various functional groups, present in starch, protein, pectin and other humic substances of organic matter are also responsible for absorption at different wavelengths. In raw spectra or original spectra, very few peaks are visible, but in case of first derivative transformed reflectance spectra, so many peaks are available, thus indicating the usefulness of first derivative transformation in making spectra more informative.

Table.1 PLSR model for calibration dataset

\begin{tabular}{|c|c|c|c|c|c|}
\hline $\begin{array}{l}\text { Sr } \\
\text { No }\end{array}$ & $\begin{array}{c}\text { Soil microbial } \\
\text { parameters }\end{array}$ & No. of factors & $\begin{array}{c}\text { No. of calibration } \\
\text { samples }(\mathbf{N})\end{array}$ & $\mathbf{R}^{2}$ & RMSE \\
\hline 1 & $\mathrm{MBC}\left(\mu \mathrm{gg}^{-1}\right) *^{1}$ & 2 & $109 *^{2}$ & 0.44 & 1.99 \\
\hline 2 & DHA $\left(\mu \mathrm{g} \mathrm{TPF}^{-1} \mathrm{hr}^{-1}\right) * 1$ & 1 & $108 *^{2}$ & 0.36 & 0.23 \\
\hline
\end{tabular}


Table.2 PLSR model for validation dataset

\begin{tabular}{lcccccc}
\hline Sr No & $\begin{array}{c}\text { Soil microbial } \\
\text { parameters }\end{array}$ & N & SD & $\mathbf{R}^{2}$ & RMSEP & RPD \\
\hline 1 & ${\mathrm{MBC}\left(\mu \mathrm{g} \mathrm{g}^{-1}\right)^{*}}_{2}$ & 57 & 2.81 & 0.25 & 2.45 & 1.15 \\
$\mathrm{DHA}\left(\mu \mathrm{gPF}^{-1} \mathrm{hr}^{-1}\right)^{*}$ & 54 & 0.35 & 0.16 & 0.31 & 1.13 \\
\hline
\end{tabular}

$\mathrm{N}=$ no of samples used for validation.

Fig.1 Study area: Ladian Khurd village of Ludhiana district of Punjab, India

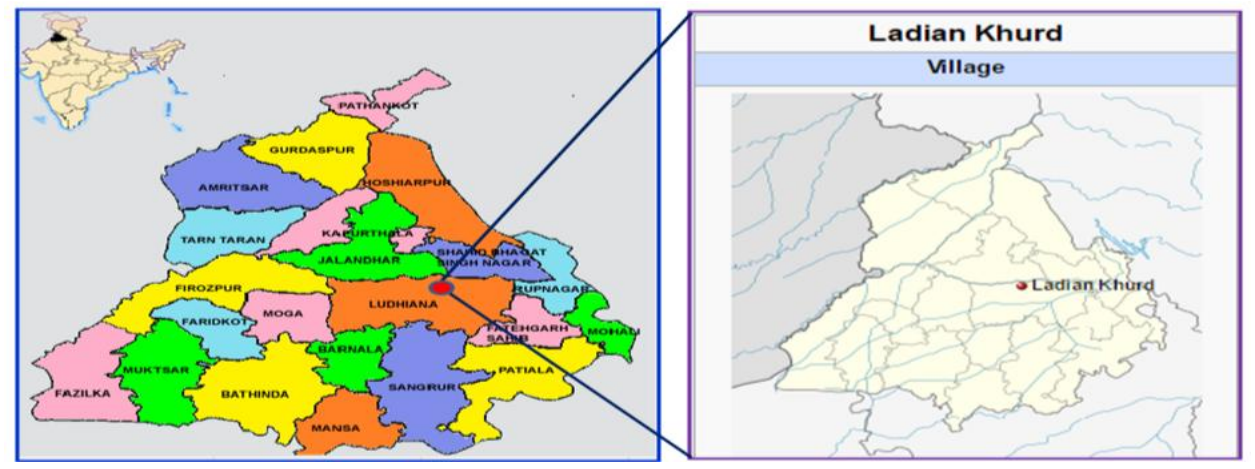

Fig.2 Original reflectance spectra $(10 \mathrm{~nm})$ of soil samples

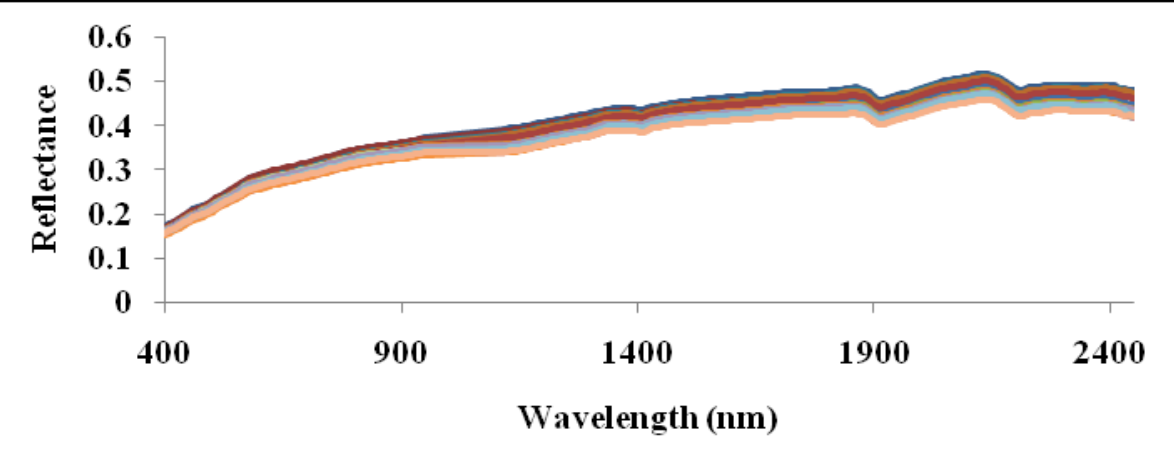

Fig.3 First derivative reflectance spectra (transformed) of soil samples

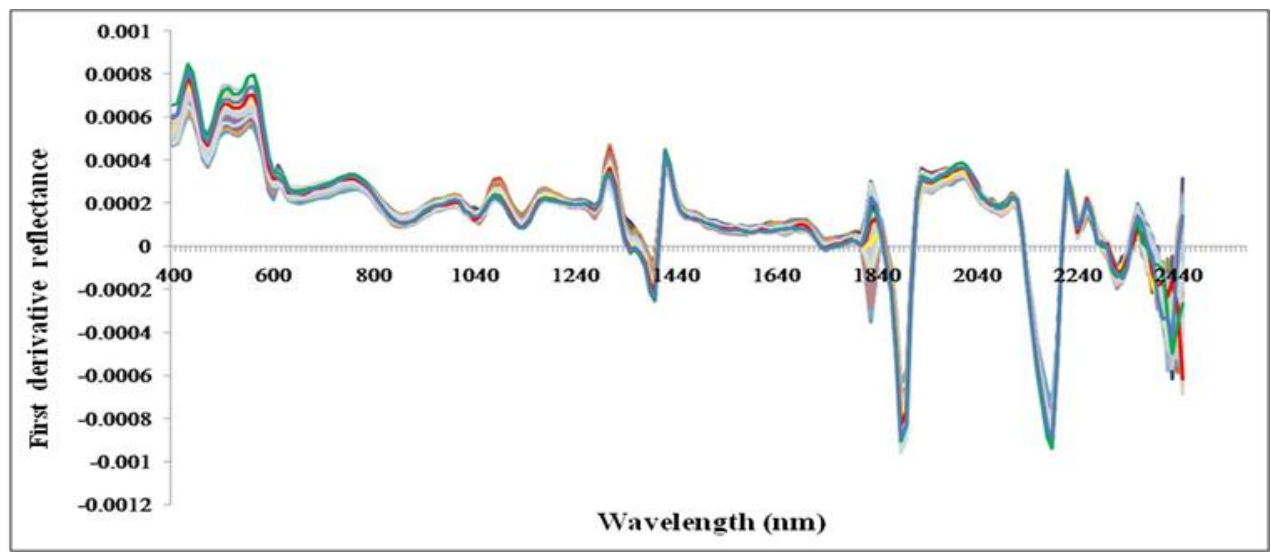


Fig.4 \&5 Correlation of MBC and DHA with reflectance at different wavelengths
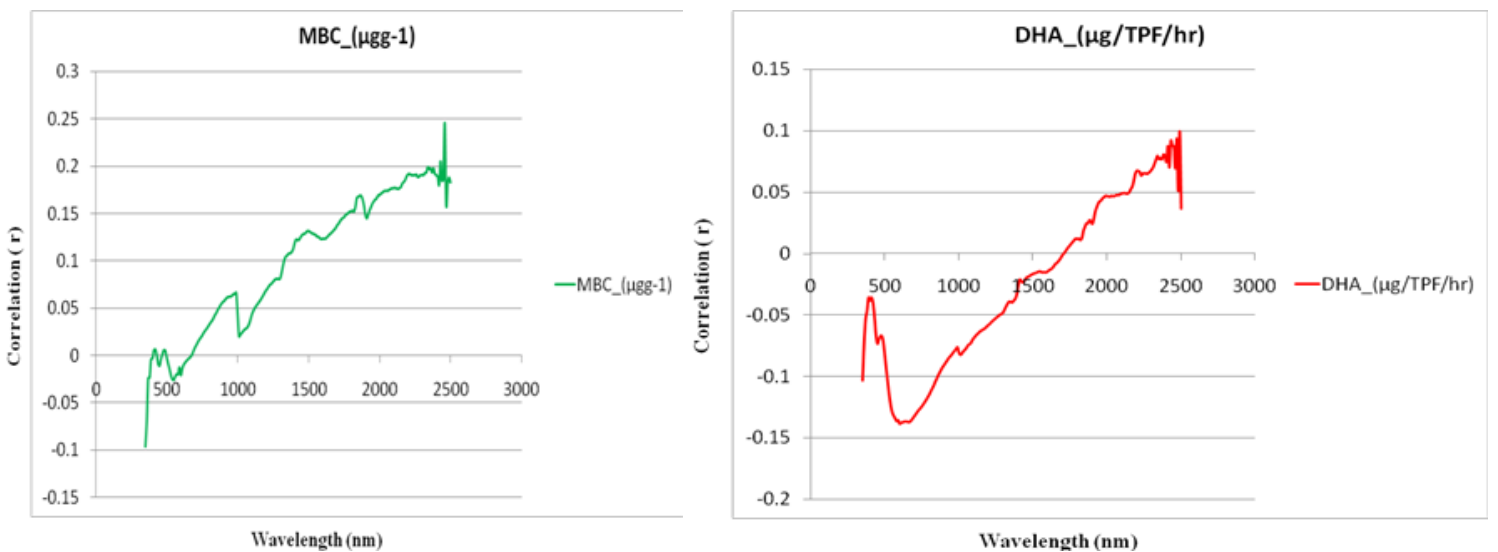

Fig.6\&7 Scatter plots of MBC and DHA in calibration dataset
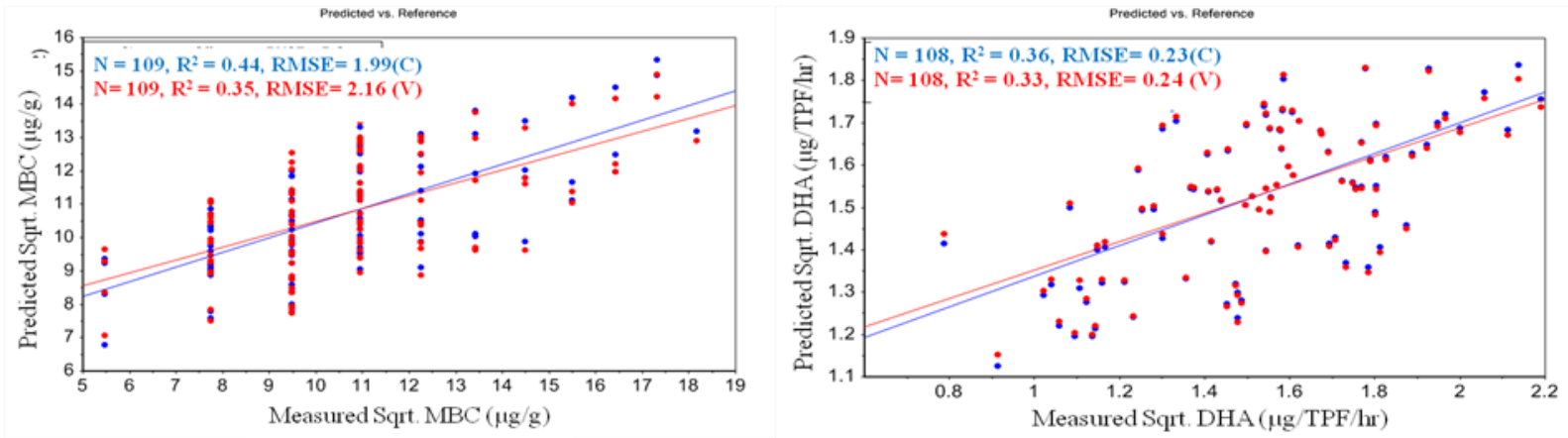

Fig.8\&9 Scatter plots of MBC and DHA in validation dataset
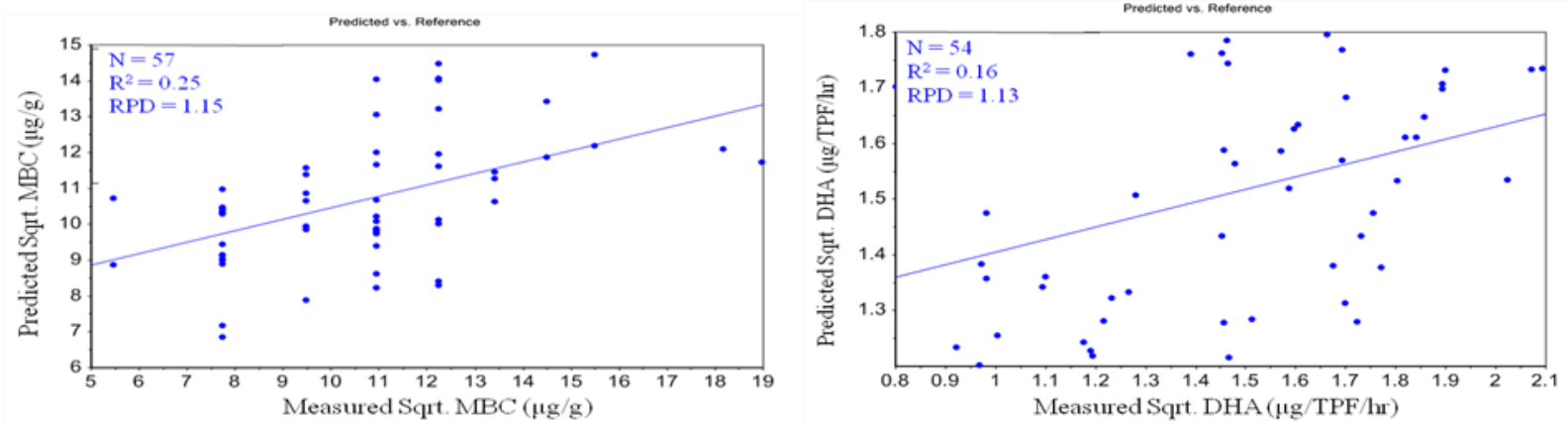

Correlation of spectra with soil microbiological parameters

and negative correlation at different wavelengths (Fig. 4 and 5).

The statistical correlation between raw soil reflectance data at different wavelengths (350 - $2500 \mathrm{~nm}$ ) and various soil microbiological properties was carefully examined. Such statistical correlation showed both positive

The correlation of soil microbial biomass carbon (MBC) with soil reflectance was, however, initially negative in visible region but almost positive in infrared regions. Dehydrogenase activity (DHA) showed 
negative correlation up to $1700 \mathrm{~nm}$ and then positive correlation up to $2500 \mathrm{~nm}$.

\section{Partial least square regression modeling (PLSR modeling)}

PLSR modeling technique was used for data analysis in calibrating the reflectance spectra with various microbiological properties by relating the two data matrices (reflectance and microbial parameter) through a linear multivariate model. PLSR model provided good correlation between soil spectra and two microbiological properties (MBC and DHA).

First derivative soil reflectance data of calibration dataset were calibrated with soil fertility properties using PLSR model. The statistical parameters of calibration datasets viz number of factors, number of samples used for calibration model $(\mathrm{N})$, and coefficient of determination $\left(\mathrm{R}^{2}\right)$, root mean square error (RMSE) of calibration values for different soil properties are presented in Table 1. In calibration data set, the values of coefficient of determination $\left(\mathrm{R}^{2}\right)$ and RMSE values for $\mathrm{MBC}$ were respectively 0.44 and 1.99. In case of DHA, these values were respectively 0.36 and 0.23 . Thus RMSE value was higher for MBC than DHA. But both the parameters had lower $\mathrm{R}^{2}$ values. The moderately poor calibration of PLSR models for MBC and DHA may be due to narrow variations in soil sample as compared to other soil parameters and also due to narrow variation in soil spectra. The scatter plots of measured and predicted values (in square root transformation) for $\mathrm{MBC}$ and $\mathrm{DHA}$ in calibration datasets are presented in Figure 6 and 7. Out of 170 samples, we have taken 113 samples for calibration, but for predicting microbiological parameters, sample size has been reduced to some extent (for MBC, 109 and for DHA, 108 samples) for better prediction purpose. The outliers samples were omitted and through this, we have tried to find out the exact sample size, should be used for calibrating the model for improving prediction accuracy.

The indices of validation dataset viz. coefficient of determination $\left(\mathrm{R}^{2}\right)$, root mean square error of prediction (RMSEP) and ratio of performance to deviation (RPD) were used to evaluate the predictive performance of the PLSR model for the two microbiological attributes. Higher $\mathrm{R}^{2}$ and RPD values and lower RMSEP suggest better prediction capabilities of the spectral model. Our study revealed that $R^{2}$ and $R P D$ values were lower for these $\mathrm{MBC}$ and $\mathrm{DHA} \quad\left(\mathrm{R}^{2}=0.25\right.$ and $\mathrm{RPD}=1.15$ for $\mathrm{MBC}$ and $\mathrm{R}^{2}=0.16, \mathrm{RPD}=1.13$ for DHA respectively). Chang et al., 2001 gave a classification on prediction abilities based on RPD values and termed excellent, moderately acceptable and poor prediction capabilities if the range of RPD values $>2.0$, 1.4-2.0 and $<1.4$ respectively. Based on this classification, our result belongs to poor prediction categories. We ascribe these to small variation in spectra and also to collection of samples from farmers' field per se in natural condition rather than under controlled condition or laboratory environment without resorting to any artificial treatment. The summary of statistics for the spectral models developed by partial least square regression (PLSR) for validation datasets is given below in the Table 2. The scatter plots of measured and predicted values (in square root transformation) for $\mathrm{MBC}$ and DHA in validation datasets are presented in Figure 8 and 9. For DHA, some outliers samples have been omitted to improve validation and prediction accuracy of spectral model.

The prediction ability of any spectral model for prediction of any property mainly depends on the relationship of that property with spectrally active compounds, present in soil like clay, soil organic carbon content etc and 
these compounds have a primary response in NIR region. In our study, despite of better correlation of clay and SOC content with microbiological parameters, our spectral model failed to predict well those parameters. The lower prediction ability is mainly due to lack of their primary response in NIR region. Although some researchers reported better result for microbiological parameters like MBC $\left(\mathrm{R}^{2}=0.95, \mathrm{RPD}=4.40\right.$; Couteaux et al., 2003) and for DHA $\left(\mathrm{R}^{2}=0.96, \mathrm{RPD}=1.89\right.$; Cohen et al., 2005); they obtained such good results for microbiological properties as these properties were mainly comprising of organic compounds. The functional groups present in such organic compounds can cause change in spectral reflectance characteristics by absorbing radiation in NIR region.

Better prediction ability of microbiological parameters can be explained by the variation carbon use efficiency and physiological status of microbial community, having a characteristics influence on spectra. But Reeves et al., 2000 achieved poor prediction for enzymatic activities like dehydrogenase activities and also other enzymatic activities with a poor $R^{2}$ value $\left(R^{2}<0.75\right)$. Our study is also in conformation with this result. The poor prediction capabilities of our spectral model might also be related to high SOC content, presence of three different land use types and consequently to the qualitative and quantitative variability in the SOC pool of the landscape. Thus, our results convey highly site specific nature of the spectral approach for assessing soil microbiological parameters. Also, our study suggests making spectral library as exhaustive as possible for assessing microbiological variables reliably. Great expansion of research work on microbial communities and properties under natural conditions is also needed as these are sensible and reliable indicators of soil quality (Dick et al., 1996), which will help to assess soil degradation process and to formulate better management strategies and also to assess whether this new technique has the potential to replace the cumbersome analysis especially for microbiological parameters.

The study mainly focused on the use of visible-near-infrared spectroscopy (VNIR region) for the rapid evaluation of soil microbiological properties instead of laborious, destructive and time consuming chemical analysis. Prediction ability of the PLSR model was greatly limited by the limited variability in data and also due to relatively smaller size. Another factor holding back the prediction performance of the PLSR model can be natural per se state of the samples as opposed to their collection under controlled environment. Use of samples combined from the three land use types may be another factor coming in the way of prediction ability of VIS-NIR models. Our results do not substantiate other studies that report reliable prediction of these key microbiological parameters as suggested by high $\mathrm{R}^{2}$ and high RPD values. Even when predicted by conventional chemical methods, MBC and DHA vary considerably. We also suggest employing selective regions of spectra as indicated by correlation analysis for better prediction of these properties.

\section{References}

Amador, J.A., Glucksman, A.M., Lyons, J. B. and Gorres, J.H. 1997. Spatial distribution of soil phosphatase activity within a riparian forest. Soil Sci., 162: 808-825.

Boerner, R.E.J., Decker, K.L.M. and Sutherland, E.K. 2000. Prescribed burning effects on a soil enzyme activity in a southern Ohio hardwood forest: a landscape-scale analysis. Soil Biol. Biochem., 32:899-908.

Bowers S A and Hanks R J (1965) Reflectance of radiant energy from soils. Soil. Sci. Soc. Am. J., 100:130-38.

Cao, C., Jiang, S., Ying, Z., Zhang, F. and Han, X. 2011. Spatial variability of soil nutrients and microbiological properties after the 
establishment of leguminous shrub Caragana microphylla Lam. Plantation on sand dune in the Horqin sandy land of northeast China. Ecol Eng., 37: 1467-1475.

Chang, C.W., Liard, D.A., Mausbach, M.J. and Hurburgh, C.R. 2001. Near-infrared reflectance spectroscopy-principal components regression analyses of soil properties. Soil. Sci. Soc Am. J., 65(2): 480490.

Cohen, M.J., Prenger, J.P. and DeBusk, W.F. 2005. Visible-near infrared reflectance spectroscopy for rapid, non-destructive assessment of wetland soil quality. $J$ Environ. Qual., 34: 1422-1434.

Couteaux, M.M. Berg, B. and Rovira, P. 2003. Near infrared reflectance spectroscopy for determination of organic matter fractions including microbial biomass in coniferous forest soils. Soil Biol. Biochem., 35: 15871600.

Dick, R.P., Breakwell, D.P. and Jurco, R.F. 1996. Soil enzyme activities and biodiversity measurements as integrative microbiological indicators. In: Doran, J.W., Jones, A.J., editors. Methods for assessing soil quality. Soil. Sci. Soc. Am. J., special publication, 49: Madison, p: 247-271.

Gregorich E G, Greer K J, Anderson D W and Liang (1998) Carbon distribution and losses: erosion and depositional effects. Soil. Till. Res.47: 291-302.

Jackson M L (1967) Soil chemical Analysis, Prentice Hall India Pvt. Ltd, New Delhi.Pp 234-246.

Janzen H H (1993) Soluble salts. In: Carter, M R (Ed) Soil sampling and Methods of Analysis, CRC Press Inc., Florida, pp. 161-166.

Kourtev, P.S., Ehrenfeld, J.G., and Haggblom, M. 2002. Exotic plant species after the microbial community structure and function in the soil. Ecology., 83: 3152-3166.

Reeves, III., J.B., Macarty, G.W. and Meisinger, J.J. 2000. Near-infrared reflectance spectroscopy for determination of biological activity in agricultural soils. $J$. Near Infrared Spectrosc. 8: 161-170.

Savitzky A and Golay M J E (1964) Smoothing and differentiation of data by simplified least squares procedure. Anal. Chem., 36: 162739.

Shepherd D K and Walsh G M (2002) Development of reflectance spectral libraries for characterization of soil properties. Soil. Sci. Soc. Am. J.,66: 988-998.

Tabatabai M A (1982) Soil enzymes. In: Page, A L (Ed), Methods of Soil Analysis. Part 2. Chemical and Microbiological Properties. Madison, 903-947.

Walkey A, Black IA. 1934. An examination of the Degtjareff method for determining soil organic matter and a proposed modification of the chromic acid titration method. Soil Sci. 37: 29-37.

Wetzel D L (1983) Near-infrared reflectance analysis: Sleeper among spectroscopic techniques. Anal. Chem.55: 1165A-1176A.

Xu, X.F., Schimel, J.P., Thornton, P.E. and Post, W. M. 2013. A global analysis of soil microbial biomass carbon nitrogen and phosphorus in terrestrial ecosystem. Glob. Ecol. Biogeogr., 22: 737-749.

Xu, X.F., Schimel, J.P., Thornton, P.E., Song, X. Yuan, F.M. and Goswami, S. 2014. Substrate and environmental controls on microbial assimilation of soil organic carbon: a framework for earth system model. Ecol. Lett., 17: 547-555.

\section{How to cite this article:}

Bhabani Prasad Mondal, Bharpoor S. Sekhon, Sandeep Sharma, Manjeet Singh, Rabi N. Sahoo, Arijit Barman, Yagani Sinha, Arghya Chattopadhyay and Koushik Banerjee. 2017. VIS-NIR Reflectance Spectroscopy for Assessment of Soil Microbiological Properties. Int.J.Curr.Microbiol.App.Sci. 6(12): 719-728. doi: https://doi.org/10.20546/ijcmas.2017.612.075 